Published in Surface and Interface Analysis (2005) 37(1):33-41

\title{
Infrared Ellipsometry of Interdiffusion in Thin Films of Miscible Polymers
}

\author{
P. Duckworth, H. Richardson, C. Carelli and J.L. Keddie*
}

Department of Physics, School of Electronics and Physical Sciences, University of Surrey, Guildford, Surrey GU2 7XH, United Kingdom

\begin{abstract}
A new application of infrared ellipsometry is reported. Specifically, the interdiffusion between thin films of miscible polymers (poly(methyl methacrylate) and poly(vinylidene fluoride)) is detected in a non-invasive measurement. A novel technique of data analysis for interdiffusion was developed and is described. The validity of the approach is supported by simulations of diffusion in a bilayer. The onset of extensive interdiffusion over a time period of $15 \mathrm{~min}$. occurs at a temperature of $160{ }^{\circ} \mathrm{C}$. At a temperature of $190{ }^{\circ} \mathrm{C}$, the data show that complete mixing of a bilayer ( $850 \mathrm{~nm}$ thick) occurs within $30 \mathrm{~s}$, which is consistent with previously reported values of the mutual diffusion coefficient. IR ellipsometry is non-invasive, applicable at elevated temperatures, and relatively fast and sensitive. Although in these measurements, it was unable to determine a concentration profile at the interface, IR ellipsometry was successfully used to detect when interdiffusion had occurred. Hence, it is a useful means for screening polymer pairs for miscibility.
\end{abstract}

Running head: Infrared Ellipsometry of Polymer Interdiffusion

Key words: interfaces, infrared, ellipsometry, thin films, diffusion, miscible

\footnotetext{
${ }^{*}$ Corresponding author. E-mail: j.keddie@surrey.ac.uk
} 


\section{Introduction}

Measurements of interdiffusion at polymer/polymer interfaces provide essential knowledge for polymer co-extrusion [1], the welding of polymers [2], adhesion development $[3,4]$, and the processing of polymer blends. A large body of knowledge describing polymer diffusion theory [5], supported by extensive experimental data [6], already exists in the literature.

Numerous techniques for the measurement of interdiffusion in miscible polymer pairs have been established, especially within the past two decades. Techniques with relatively low resolution but that are suitable for diffusion in bulk materials usually require the preparation of cross-sectional slices across the broadened, diffuse interface. One pioneering approach of this type was infrared (IR) microdensitometry $[7,8]$, which profiles the concentration gradient across distances of $\mathrm{mm}$. Techniques that offer higher resolution, and that have therefore been applied to studies of interdiffusion in polymer thin films, include ion beam analysis $[9,10]$, transmission electron microscopy [11], neutron reflectivity [12], small angle X-ray scattering [13, 14], dynamic SIMS [15,16], IR microscopy [17], and Raman microspectroscopy [18, 19], to name the most common ones. Quite often, interdiffusion occurs at elevated temperatures; the diffusion couples are then quenched to room temperature for analysis.

Ellipsometry is yet another technique that has been employed as a probe of interfacial width in both miscible and immiscible polymer systems. As a technique that relies on the analysis of the change in the state of polarisation of light after its reflection from an interface, ellipsometry is most effective when there is a significant difference in the 
refractive index, $n$, of the two media at an interface. Ellipsometry cannot be applied to polymer pairs that have the same - or highly similar - refractive index. Some polymer pairs that are able to provide sufficient contrast and that have been studied using visible-light ellipsometry are poly(styrene) (PS)/ poly(methyl methacrylate) (PMMA) [20,11], bisphenol A poly(carbonate)/styrene-acrylonitrile (SAN) random copolymer [21, 20], SAN copolymer/PMMA [22, 23, 24], PMMA and PS with MMA-S copolymers [23], and PS/poly(vinyl methyl ether) $[25,26]$. In modelling the data, the interfacial region is usually described as a single layer with a refractive index that is intermediate between the two polymers at the interface. It is exceedingly difficult to analyse the ellipsometry data if the film thicknesses are not already known, because of the correlation between the parameters during the data modeling.

Despite this progress in technique development, and despite the wide number of techniques available, there are still limitations in the experimental study of polymer interdiffusion. There is a particular need for a fast, simple laboratory technique that can be used to screen thin film polymer pairs at elevated temperatures in order to determine miscibility and interdiffusion. In this paper, we show that ellipsometry using IR radiation provides a simple, non-invasive means to determine if polymer pairs are miscible and to determine the minimum temperature at which diffusion is significant. In those cases in which the amount of material is limited, or when diffusion is very slow, it is particularly helpful to have a technique to probe diffusion in thin films, rather than in bulk samples.

With its instrumentation being developed only within the past decade [27], IR ellipsometry is a relatively new technique. Consequently, there are many potential 
uses that have not yet been realised, leaving great scope for further development. IR ellipsometry can detect layers that are only a few nm thick [28, 29, 30]. For films that are tens of nm thick, the uncertainty of a thickness measurement is typically $1 \mathrm{~nm}$ under ideal conditions [28].

The practical applications of IR ellipsometry to polymers have been rather limited so far. Previous polymeric uses of IR ellipsometry include the detection of chemical changes induced by plasma treatment $[30,31,32,33]$, the determination of crosslinking reactions $[34,35]$, and the probing of bonding at interfaces $[28,30]$. There are several examples of IR ellipsometry determining the structure and composition of polymer layers on solid, inorganic substrates, such as silicon or gold $[31,32,35,36]$. In one of the first applications of IR ellipsometry specifically to polymer/polymer interfaces, Röseler and Korte determined the thickness of a fluorinated polymer layer on a thick polyethylene substrate [37]. The thickness of poly(dimethyl siloxane) films on thin films of glassy polymers has also been determined by the technique [34].

IR ellipsometry has never been reported as a probe of diffusion. Nevertheless, the technique offers an attractive combination of capabilities for studying polymer interdiffusion in thin films. In particular, IR ellipsometry can probe films noninvasively at elevated temperatures. It can acquire data within a few minutes, allowing diffusion processes to be followed over time. As will be shown here, data analysis does not always require fitting to a model. 
Although most polymers are immiscible [6], there are a few well-known miscible polymer pairs. The miscibility of poly(methyl methacrylate) (PMMA) and poly(vinylidene fluoride) (PVDF) over a wide range of compositions is well established $[38,39]$. Their miscibility is attributed to hydrogen bonding between the carbonyl group $(\mathrm{C}=\mathrm{O})$ of PMMA and the $\mathrm{CH}_{2}$ groups of PVDF [38]. In the visible range of the spectrum, $n$ for PVDF and PMMA are similar. Specifically, at a wavelength of $500 \mathrm{~nm}$, measurements in our laboratory find $n=1.53$ for PMMA and $n=1.45$ for PVDF. As a result, there is very little contrast between the two, making ellipsometry analysis difficult when using visible light. In the infrared region, on the other hand, there are large differences in index, as will be shown in this paper. Hence, there is contrast between the two polymers that facilitates ellipsometry analysis.

\section{Experimental Procedure}

\section{Materials and Thin Film Deposition}

Powders of PVDF (Aldrich Chemical Co., Gillingham, UK) and PMMA (Polymer Laboratories, UK) with weight-average molecular weights of $M_{\mathrm{w}}=1.8 \times 10^{5} \mathrm{gmole}^{-1}$ (polydispersity index of $M_{\mathrm{w}} / M_{\mathrm{n}}=2.54$ ) and $M_{\mathrm{w}}=1.41 \times 10^{5} \mathrm{gmole}^{-1}\left(\mathrm{M}_{\mathrm{w}} / \mathrm{M}_{\mathrm{n}}=1.01\right)$, respectively, were used as received.

Thin films were deposited by spin-casting dilute polymer solutions onto single crystal silicon wafers. Solutions were prepared by dissolving PMMA in toluene and PVDF in dimethyl formamide. The silicon was heavily p-doped so that it was IR reflective. Film thickness was measured using spectroscopic ellipsometry (J.A. Woollam Co., Inc., Lincoln, NE, USA). 
Bilayers of the polymers were prepared by first depositing one of the polymers onto a silicon substrate in the usual manner. The second polymer of the opposite type was then spin-cast onto a clean, glass substrate. This film was next floated onto the surface of de-ionised water and slowly lowered onto the film on silicon. Typically the bilayers consisted of a $300 \mathrm{~nm}$ PMMA film and a $550 \mathrm{~nm}$ PVDF film.

Preliminary experiments found that the IR ellipsometry spectra from polymer bilayers changed significantly after heating at low temperatures. We speculate that a lowtemperature heat treatment was able to liberate water that had been trapped at the PVDF/PMMA interface, to accelerate the loss of solvent from the films, and to increase the volume relaxation rate [40] of the polymers. IR ellipsometry is capable of detecting any of these processes. To separate out these effects from interdiffusion, it was therefore necessary to "condition" the bilayers prior to IR ellipsometry analysis by heating to $90{ }^{\circ} \mathrm{C}$ for $30 \mathrm{~s}$. Heating a second time to the same temperature caused no additional changes, suggesting that the bilayer structure was then stable.

\section{IR Ellipsometry Technique}

Ellipsometry spectra were obtained from an FTIR ellipsometer (Model GESP5-FTIR, SOPRA Sa., Bois-Colombes, France). In a typical measurement, 16 scans were performed for each spectrum, and 16 spectra were averaged. A spectral resolution of $8 \mathrm{~cm}^{-1}$ was set over the spectral range of $650-4000 \mathrm{~cm}^{-1}$. The data acquisition time with these conditions was approximately two hours. All spectra were obtained at an angle-of-incidence of $65^{\circ}$, as measured from the normal to the substrate. 
For in situ measurements, bilayer films were heated in air on a heating-stage (Linkam Scientific Instruments Ltd., Tadworth, Surrey, UK) at various temperatures while being analysed by the ellipsometer. In an experiment to explore the temperature dependence of interdiffusion, the temperature was increased in increments of $5^{\circ} \mathrm{C}$ from $130{ }^{\circ} \mathrm{C}$ to $190^{\circ} \mathrm{C}$. The temperature was held constant at each increment for 15 min., during which time an IR ellipsometry scan was made. This faster data acquisition was obtained by collecting 16 scans for each spectrum with a resolution of $16 \mathrm{~cm}^{-1}$ and averaging four spectra.

\section{Results and Discussion}

In an ellipsometry measurement, the change in the state of polarisation caused by a reflection from the sample surface is described by the ellipticity, $\rho$, which is given as

$$
\rho=\tan \psi \exp (\mathrm{i} \Delta)
$$

where $\psi$ and $\Delta$ are the ellipsometry parameters. The relative change in the amplitude of the light is described by $\psi$, and the change in the relative phase is described by $\Delta$.

In the visible region of the spectra, there is only a small difference in the refractive indices of PMMA and PVDF. In the infrared region, there are large differences that result in differences in the ellipsometry spectra for the two polymers. As an example, ellipsometry spectra obtained from single films of PMMA (590 nm thick) and PVDF (547 $\mathrm{nm}$ thick) are presented in Figure 1. The spectra from the Si substrate (with its native oxide layer) are shown for comparison. Characteristic absorptions were identified in these spectra and assigned through comparison to the literature values found for the homopolymers (PVDF [41,42,43] and PMMA [44]) and their blends $[38,39]$. Our assignments for these spectra are listed in Tables I and II. 
Inversion of the spectra in Figure 1 enabled us to obtain the refractive indices of the polymers in the IR region. In principle, these indices can be used to model data obtained from bilayers or diffusion couples of the polymers. This approach has previously been successful for the visible ellipsometry of polymer bilayers when simple slab models were employed in the data analysis [11,20-24].

Figure 2 presents the IR ellipsometry spectra obtained from a bilayer of a PMMA film on top of a PVDF film, before and after heating at $190{ }^{\circ} \mathrm{C}$ for $30 \mathrm{~s}$. The differences between the two spectra are attributed to interdiffusion between the two polymers. Before describing the analysis of these spectra, however, a brief review of the literature on PMMA/PVDF interdiffusion is required.

PMMA and PVDF were used as a model system in some of the earliest quantitative, experimental studies of polymer interdiffusion $[4,13,14]$. Their interaction parameter $\chi$ has been estimated to be -0.3 [4,13]. The diffusion of PVDF into PMMA has been found to be more rapid than PMMA diffusion into PVDF [13]. Because of the relatively poor resolutions of the techniques that were used in this previous work, higher temperatures were required to achieve faster diffusion. For PMMA of molecular weight $M_{\mathrm{w}}=150 \mathrm{k}$ diffusing at $190{ }^{\circ} \mathrm{C}$ into PVDF with $M_{\mathrm{w}}=190 \mathrm{k}$, the diffusion coefficient $D$ was found to be $3.4 \times 10^{-10} \mathrm{~cm}^{2} / \mathrm{s}$ for PVDF and $4.0 \times 10^{-11}$ $\mathrm{cm}^{2} / \mathrm{s}$ for PMMA [4]. For a symmetric interface, the root mean-square interfacial width, $w$, as a function of the diffusion time, $t$, is predicted to be $2(2 D t)^{1 / 2}$ [4]. For an asymmetric interface, however, such as will develop between PMMA and PVDF, a numerical calculation is required. For PMMA and PVDF with the molecular weights 
given above (which are very similar to those used in the present experiments), calculations [4] have predicted $w=\left(4.5 \times 10^{-7}\right) t^{1 / 2}$ (in SI units) at $190^{\circ} \mathrm{C}$. Thus, after only $30 \mathrm{~s}$. at this temperature, $w$ will be nearly $2.5 \mu \mathrm{m}$, which is much greater than the total thickness of the bilayers (typically $850 \mathrm{~nm}$ ). Hence, the bilayer in Figure 2 is expected to be essentially uniform in composition after the heat treatment.

We attempted to model the spectra in Figure 2 by employing various slab models and the refractive indices obtained from the analysis of the single films. Despite our best attempts, we were unable to model the bilayers either before or after heating at 190 ${ }^{\circ} \mathrm{C}$. We suspect that the modelling was unsuccessful because the indices obtained from thick films of the individual polymers are likely to differ from the optical constants of the polymers in the bilayer. The values of indices are highly sensitive to the density, chain conformation, and molecular orientation [45], all of which might differ between the samples. To vary simultaneously the complex refractive indices of the polymers along with their concentration profile when fitting the data to a slab model introduces too many variables to obtain a reliable solution. As an alternative method, we adopted an approach to the data analysis that has successfully been applied to other problems $[28,33,46]$, as follows.

When there is interdiffusion in a polymer bilayer, there is an enrichment in the top film of one polymer and a corresponding depletion in the concentration of the other polymer. The process of interdiffusion can therefore be described as a change in the refractive index of a surface layer. Any such alteration in a surface is readily apparent as a change in the ellipticity. The ellipsometric density, $D$, is expressed in terms of 
the ellipticity of the original "bare" surface, $\rho_{\mathrm{o}}$, and the final ellipticity, $\rho_{\mathrm{f}}$, after the addition or alteration of a surface layer:

$$
D=\ln \left(\rho_{\mathrm{o}} / \rho_{\mathrm{f}}\right)
$$

Elsewhere [33], it has been shown that $D$ is roughly proportional to the thickness of the new surface layer, $d$ :

$$
D \sim \mathrm{i} d\left(\varepsilon_{\mathrm{o}}-\varepsilon_{\mathrm{f}}\right)
$$

where $\varepsilon$ is the complex dielectric function, which is equal to the square of the complex refractive index, and the subscripts have the same meanings as in Eq. 2. This treatment is valid in the thin-film limit in which $d$ satisfies the condition $d<<$ $\lambda / 4 \pi$, where $\lambda$ is the wavelength of the radiation.

From Eq. 1 and 2, it is apparent that the real part of $D$ is a function only of $\psi$.

$$
\operatorname{Re} D=\ln \left(\tan \psi_{\mathrm{o}} / \tan \psi_{\mathrm{f}}\right)
$$

whereas the imaginary part of $D$ is a function only of $\Delta$ :

$$
\operatorname{Im} D=\mathrm{i}\left(\Delta_{\mathrm{o}}-\Delta_{\mathrm{f}}\right)
$$

It has been demonstrated elsewhere $[28,33,43]$ that if a new surface layer is created, there is a maximum, or peak, in the $\operatorname{Re} D$ spectra and a negatively-sloped step in the $\operatorname{Im} D$ spectra. The frequency at which these features appear is the characteristic frequency of the chemical group that has been created. On the other hand, if a surface layer is destroyed, there will be a minimum, or "valley", in the $\operatorname{Re} D$ spectra and a positively-sloped step in the $\operatorname{Im} D$ spectra. In this paper, the features in the $\operatorname{Re} D$ spectra are referred to as "gain" and "loss" peaks.

This approach to ellipsometry data analysis has been developed as a means of detecting a new surface layer, but it has never before been applied to the problem of 
interdiffusion. Some simulations were therefore performed to test whether $\operatorname{Re} D$ and $\operatorname{Im} D$ spectra could be used to detect interdiffusion in polymer films when the composition near the interface with air did not change. The complex refractive index of poly(dimethyl siloxane) (PDMS) was previously determined in experiments [35] and are used in the simulations. The complex refractive index of PMMA was obtained through the ellipsometry analysis of a thick sheet of the material. These indices (as a function of wavelength in the IR region) were then used to simulate ellipsometry spectra ( $\psi$ and $\Delta$ ) for a bilayer consisting of a $300 \mathrm{~nm}$ PDMS film on a $300 \mathrm{~nm}$ PMMA film on a silicon substrate. The spectra are presented in Figure 3. For comparison, the spectra of a uniform film of a 50/50 blend of PDMS and PMMA were simulated and are overlaid on the same figure. This blend layer represents the bilayer after complete interdiffusion. Conservation of volume was assumed, so the blend layer is $600 \mathrm{~nm}$ thick. There are clear differences in the spectra representing the bilayer and the blend. IR ellipsometry can therefore, in principle, detect complete interdiffusion between two polymer films.

In order to obtain simulated $D$ spectra, the simulated ellipsometry spectra in Figure 3 were then transformed using Equations 4 and 5. The resulting $\operatorname{Re} D$ spectrum, representing the changes attributed to the complete interdiffusion of the PDMS/PMMA bilayer, is shown in Figure 4. There are various features in the spectrum that are the result of chemical groups diffusing from the lower PMMA layer to the surface and from the upper PDMS layer being diluted near the surface. To examine the sensitivity of the method further, the $\operatorname{Re} D$ spectrum was similarly simulated for a $600 \mathrm{~nm}$ film with a gradient composition to represent interdiffusion at the PDMS/PMMA interface. In modelling the interface, the film was split into eight 
slabs with the volume fraction of PDMS decreasing from 1 to 0 from the bottom to the top with these steps: $0.90,0.75,0.60,0.45,0.30,0.15$. The $\operatorname{Re} D$ spectrum for this gradient layer is comparable but not identical to that for the blend layer. The magnitude of the gain and loss peaks is slightly lower, which can be explained by the fact that the change in the composition near the surface is smaller.

An additional simulation was made to test further the sensitivity of the method. The early stage of interdiffusion in a bilayer was simulated for the bilayer of a $300 \mathrm{~nm}$ PMMA film on a $300 \mathrm{~nm}$ PDMS film. A mixed region at the interface was modelled as a $100 \mathrm{~nm}$ layer consisting of equal amounts of each polymer, with the total thickness remaining fixed at $600 \mathrm{~nm}$. Figure 5 shows the $\operatorname{Re} D$ and the $\operatorname{Im} D$ spectra obtained by comparing to the ellipsometry data for the original bilayer. As in Figure 4, features in the spectra are attributed to mixing at the PDMS/PMMA interface. The magnitude of $\operatorname{Re} D$, however, is much lower in Figure 5, which is consistent with the smaller extent of mixing between the films in comparison to the gradient layer. For most features, the absolute magnitude $\operatorname{Re} D$ is less than 0.05 . Hence, although it appears that it is possible to detect a diffuse interface, high resolution in experimental measurements of $\operatorname{Re} D$ would be required. On the other hand, the features in the $\operatorname{Im} D$ spectrum are typically as high as 4 . It should be easier therefore to resolve changes in $\operatorname{Im} D$ in experiments, provided that the signal-to-noise ratio is comparable in the $\operatorname{Re} D$ and $\operatorname{Im} D$ measurements. The main outcome of the simulations is that $D$ spectra are sensitive to interdiffusion across an interface between thin films, even when the species in the lower film does not diffuse to the interface with air. Note that in the creation and analysis of $\operatorname{Re} D$ and $\operatorname{Im} D$, experimental data do not need to be fitted to a model. Instead, the approach relies on a mathematical transformation of two spectra. 
Following on from these encouraging simulations, the experimental spectra in Figure 2 were transformed via Equations 4 and 5 to obtain the $D$ spectra presented in Figure 6. Several gain and loss peaks are observed, and their assignments are listed in Table III. In identifying gain and loss peaks, both the $\operatorname{Re} D$ and the $\operatorname{Im} D$ spectra were observed. Features were assigned as a "gain" only when ReD was a maximum and at the same frequency - there was a negative slope in $\operatorname{ImD}[33]$. It should be remembered that the resolution of the ellipsometer is $8 \mathrm{~cm}^{-1}$, and hence the maxima and minima cannot be obtained with high precision. Some peaks are broad, which makes the determination of the peak maxima (or minima) less reliable. There is therefore some disagreement between the frequencies in Table III and the corresponding values in Tables I and II.

Notably, in the $\operatorname{Re} D$ spectra in Figure 6 there are gain peaks at frequencies of 1165 and $1219 \mathrm{~cm}^{-1}$, which are attributed to the characteristic frequencies for the $\mathrm{r}\left(\mathrm{CH}_{2}\right)$ and the $v\left(\mathrm{CF}_{2}\right)$ vibrations in PVDF. The development of these gain peaks is consistent with the diffusion of PVDF into PMMA and its migration towards the air interface. There are also loss peaks attributed to PMMA at 1720 and $1739 \mathrm{~cm}^{-1}$ (i.e. $v(\mathrm{C}=\mathrm{O})$ vibrations). These loss peaks might be due to PMMA groups that have been diluted by interdiffusion. A shift in the relative intensities of the two $\mathrm{C}=\mathrm{O}$ absorptions in the doublet might also be related to the existence of hydrogen bonding between the PMMA's $\mathrm{C}=\mathrm{O}$ groups and the $\mathrm{CH}_{2}$ groups of $\mathrm{PVDF}$ [38]. In the region around $1165 \mathrm{~cm}^{-1}$, it appears that a loss peak is superimposed over the PVDF $\mathrm{r}\left(\mathrm{CH}_{2}\right)$ gain peak. It is difficult to identify the frequency of the bands because of the overlap, but it is likely that the peak is associated with the $1146 \mathrm{~cm}^{-1}$ PMMA skeletal 
absorption (peak number iii in Table I). It is likely that this overlap resulted in an apparent shift in the position of PVDF's $\mathrm{r}\left(\mathrm{CH}_{2}\right)$ gain peak from $1152 \mathrm{~cm}^{-1}$ to the observed peak position of $1165 \mathrm{~cm}^{-1}$.

At this high temperature, the diffusion of PVDF to the film surface will take only a few seconds, according to an estimate using literature values for the diffusion coefficient [4]. After the same bilayer was heated at $190^{\circ} \mathrm{C}$ for a total of four min. the ellipsometry spectra did not change in comparison to the scan at $30 \mathrm{~s}$. Hence, the $\operatorname{Re} D$ and $\operatorname{Im} D$ appear as flat lines, as shown in Figure 6. This result confirms that interdiffusion was complete, i.e. a uniform film was obtained, after heating $30 \mathrm{~s}$. at $190{ }^{\circ} \mathrm{C}$.

Further experiments were conducted with the aim of observing the onset of the diffusion. A PMMA/PVDF bilayer was heated in increments of $5^{\circ} \mathrm{C}$ from a temperature of $135^{\circ} \mathrm{C}$ up to $190{ }^{\circ} \mathrm{C}$. At each increment, the temperature was held constant for 15 min. during which time an IR ellipsometry measurement was made. The results are displayed in Figure 7. $D$ spectra were obtained by comparing the spectra at a particular temperature to that at the previous temperature $\left(5^{\circ} \mathrm{C}\right.$ lower $)$. At temperatures less than $160^{\circ} \mathrm{C}$, there is no evidence for significant interdiffusion. However, starting at a temperature $160^{\circ} \mathrm{C}$, a gain peak at $1203 \mathrm{~cm}^{-1}$ was observed. It is tentatively attributed to the $v_{\mathrm{a}}^{\mathrm{o}}\left(\mathrm{CF}_{2}\right)\left(\right.$ or $\left.v_{\mathrm{s}}^{\mathrm{i}}\left(\mathrm{CF}_{2}\right)\right)$ vibration and can be explained by the diffusion of PVDF to the surface. But its apparent position is shifted downward with respect to what was found in the neat PVDF film $\left(1242 \mathrm{~cm}^{-1}\right)$. One possible reason for this is apparent shift is that superimposed in the same region there is a loss peak, which is attributed to the skeletal vibration of PMMA (i.e. peak iv at $1195 \mathrm{~cm}^{-}$ 
$\left.{ }^{1}\right)$. Indeed, a shallow minimum is observed in Figure 7 below $1200 \mathrm{~cm}^{-1}$. Finally, a loss peak at $860 \mathrm{~cm}^{-1}$ is also observed in Figure 7, which is attributed to the PVDF $v_{\mathrm{s}}(\mathrm{C}-\mathrm{C})$ vibration. It is not obviously apparent why this is a loss peak, rather than a gain, because PVDF is not depleted from the surface. If there is a conformational or orientational re-arrangement of the PVDF molecules as a result of the diffusion, however, a change in the intensity of the absorption would be expected. The same type of loss peak was seen in Figure 6 for the bilayer heated at $190{ }^{\circ} \mathrm{C}$ for $30 \mathrm{~s}$.

Figure 7 shows that the diffusion proceeds up until a temperature of $175^{\circ} \mathrm{C}$ is reached. The featureless $D$ spectra at $180^{\circ} \mathrm{C}$ indicate that no further changes in the bilayer structure have occurred over the previous $15 \mathrm{~min}$. at this temperature. This result is interpreted as representing the point at which a uniform film has been achieved by the interdiffusion of the miscible polymers. No further changes were observed at higher temperatures (up to $190{ }^{\circ} \mathrm{C}$ ).

As a test of these interpretations, the same experiments were repeated with the only difference being that the bilayer was reversed; a PVDF film was placed over a PMMA film. For the polymer molecular weights used here, the diffusion coefficient of PMMA at $190{ }^{\circ} \mathrm{C}$ is lower than that of PVDF by about an order of magnitude [4]. Hence, it is expected that it will take longer for PMMA to reach the surface in comparison to PVDF. During interdiffusion between the two polymers, there will be an asymmetric interface. Furthermore, it is expected that in the reversed bilayer, gain peaks from PMMA and loss peaks from PVDF will be observed. 
These expectations were broadly realized in the experiments. Figure 8 shows the $D$ spectra for the reversed bilayer after $30 \mathrm{~s}$. and $4 \mathrm{~min}$. at $190{ }^{\circ} \mathrm{C}$. These spectra are quite different from those obtained previously from PMMA on PVDF/Si. Clearly, IR ellipsometry can distinguish between the two types of bilayers. As presented in the analysis in Table IV, there are some gain peaks associated with PMMA and loss peaks associated with PVDF. Specifically, the gain peaks at 764 and $1381 \mathrm{~cm}^{-1}$ provide evidence for the enrichment of the $\mathrm{CH}_{3}$ groups of PMMA near the film surface. The large gain peak at $1152 \mathrm{~cm}^{-1}$ is attributed to the skeletal absorption of PMMA (peak iii), which is one of its major bands as seen in Figure 1a. Loss peaks at 914 and $980 \mathrm{~cm}^{-1}$, which are assigned to $v_{\mathrm{s}}(\mathrm{C}-\mathrm{C})$ and PVDF skeletal vibrations, respectively, are explained by the depletion of PVDF in the top film. The positions of these two peaks are shifted from what was observed in the neat PVDF films (Figure $1 \mathrm{~b}$ and Table II). However, it is likely that a PMMA gain peak attributed to $\delta\left(\mathrm{CH}_{3}-\mathrm{O}\right)$ at $991 \mathrm{~cm}^{-1}$ is also present in this region. The PVDF peaks are therefore shifted to different apparent positions because of this interference.

There is some evidence in Figure 8 for further changes in the film structure between $30 \mathrm{~s}$ and $4 \mathrm{~min}$. This finding is consistent with the expectation of slower PMMA diffusion in comparison to the PVDF diffusion observed previously (Figure 6).

A reversed bilayer was heated in $5^{\circ} \mathrm{C}$ increments between $135^{\circ} \mathrm{C}$ and $190{ }^{\circ} \mathrm{C}$, for comparison to the experiment in Figure 7. The results from the reversed bilayer analysis are presented in Figure 9. There are gain peaks at 872, 1157, 1249 and 1381 $\mathrm{cm}^{-1}$. Our interpretation is that these correspond to PMMA groups diffusing into the PVDF and enriching this upper layer. These absorptions are attributed to PMMA 
skeletal (peak iii), $v(\mathrm{C}-\mathrm{O})$ (peak v), and $\delta\left(\alpha-\mathrm{CH}_{3}\right)$ (peak vii) vibrations at 1157,1249 and $1381 \mathrm{~cm}^{-1}$, respectively. Molecular rearrangement of PVDF can explain the gain in the $v_{\mathrm{s}}(\mathrm{C}-\mathrm{C})$ absorption assigned to $872 \mathrm{~cm}^{-1}$. Notably, in the other bilayer (PMMA on PVDF) a loss peak was observed in the same region. The opposite result in the reversed bilayer is therefore consistent with the results in Figure 7. The fact that the spectra obtained from the reversed bilayer are significantly different in an explainable way lends further confidence to our data interpretation. As was observed previously, the $D$ spectra are flat when interdiffusion is complete. In this case, the interdiffusion is complete at a temperature of $180^{\circ} \mathrm{C}$.

\section{Summary and conclusions}

IR ellipsometry has been developed as a probe of interdiffusion in polymer bilayer films with a total thickness of about $850 \mathrm{~nm}$. The technique has been used at temperatures as high as $190^{\circ} \mathrm{C}$. The time for the acquisition of quality spectra (i.e. with a sufficient signal-to-noise ratio) can be as short as $15 \mathrm{~min}$.

Because of its sensitivity to chemical groups, IR ellipsometry offers contrast between two polymers even when they have similar values of the real part of their refractive

index. It was shown here that interdiffusion in the miscible polymer pair of PMMA and PVDF can be probed through measurements of the ellipsometric density, $D$. Measurements of $D$ corresponding to the bilayer before and after interdiffusion were used to determine when a species had diffused to the surface. IR ellipsometry was able to distinguish between interdiffusion in a bilayer of PMMA on PVDF versus interdiffusion in the reversed bilayer of PVDF on PMMA. A key advantage of this approach to data analysis is that a model does not need to be applied. Simulations of 
$D$ spectra for fully-blended and partially-interdiffused films support this experimental approach. The onset of extensive interdiffusion between PVDF and PMMA films was detected at a temperature of $160^{\circ} \mathrm{C}$.

An obvious application of the methodolgy presented here is as a quick check on the miscibility between polymer films. The IR ellipsometry technique can certainly be extended to other IR active substances, including ceramics. Our approach to data analysis has the limitation that it cannot provide depth profiles of polymer concentration. Its simplicity and ease of use, however, make it a highly attractive complementary technique to use with depth-profiling methods.

\section{Acknowledgements}

Funding for H.R. and C.C. and for the original purchase of the visible and IR ellipsometers was provided by the UK's Engineering and Physical Sciences Research Council. We are grateful to Dr Tim Simpson, formerly at the University of Surrey, for helpful discussions and practical assistance.

\section{References}

1 ) Kim JK, Han CD. Polym. Eng. Sci. 1991; 31: 258.

2 ) Jud K, Kausch HH, Williams JG. J. Mater. Sci. 1981; 16: 204.

3 ) Schnell R, Stamm M, Creton C. Macromolecules 1998; 31: 2284.

4) Wu S, Chuang H-K. J. Pol. Sci.: Polym. Phys. Ed. 1986; 24: 143.

5) Brochard F, Jouffroy J, Levinson P. Macromolecules 1983; 16: 1638.

6) Jones RAL, Richards RW. In Polymer at Surfaces and Interfaces, Cambridge University Press: Cambridge, 1999; pp. 127-186.

7) Klein, J. Nature 1978; 271: 143. 
8) Klein J, Briscoe BJ. Polymer 1976; 17: 481.

9) Composto RJ, Kramer EJ. J. Mater. Sci. 1991; 26: 2815.

10) Mills PJ, Green PF, Palmstrom CJ, Mayer JW, Kramer EJ. Appl. Phys. Lett. 1984; 45: 957.

11) Kressler J, Higashida N, Inoue T, Heckmann W, Seitz F. Macromolecules 1993; 26: 2090 .

12) Bucknall DG, Butler SA, Higgins JS. Macromolecules 1999; 32: 5453.

13) Garbella RW, Wendorff JH. Makromol. Chem. 1988; 189: 2459.

14) Garbella RW, Wendorff JH. Makromol. Chem., Rapid Commun. 1986; 7: 591.

15) Pu Y, Rafailovich MH, Sokolov J, Gersappe D, Peterson T, Wu WL, Schwarz

SA. Phys. Rev. Lett. 2001; 87: 206101.

16) Zheng X, Rafailovich M, Sokolov J et al. Phys. Rev. Lett. 1997; 79: 241.

17) Neuber R, Schneider HA. Polymer 2001; 42: 8085.

18) Hajatdoost S, Olsthoorn M, Yarwood J. Appl. Spectrosc. 1997; 51: 1784.

19) Hajatdoost S, Yarwood J. Appl. Spectrosc. 1996; 50: 558.

20) Higashida N, Kressler J, Yukioka S, Inoue T. Macromolecules 1992; 25: 5259.

21) Li HG, Yang Y, Fujitsuka R, Ougizawa T, Inoue T. Polymer 1999; 40: 927.

22) Yukioka S, Inoue T. Polymer Comm. 1991; 32: 17.

23) Yukioka S, Inoue T. Polymer 1993; 34: 1256.

24) Yukioka S, Nagato K, Inoue T. Polymer 1992; 33: 1171.

25) Sauer BB, Walsh DJ. Macromolecules 1994; 27: 432.

26) Sauer BB, Walsh DJ. Macromolecules 1991; 24: 5948.

27) Canillas A, Pascual E, Drévillon B, Rev. Sci. Instrum. 1993; 64: 2153.

28) Simpson TRE, Keddie JL. J. Adhes. 2003; 79: 1207. 
29) Tsankov D, Hinrichs K, Röseler A, Korte EH. Phys. Stat. Sol. (A) 2001; 188: 1319.

30) Drévillon B. Thin Sol. Films 1998; 313-314: 625.

31) Bungay CL, Tiwald TE, Thompson DW, DeVries MJ, Woollam JA, Elman JF. Thin Sol. Films 1998; 313-314: 713.

32) Yan L, Gao X, Bungay C, Woollam JA. J. Vac. Sci. Technol. A 2001; $19: 447$.

33) Vallon S, Drévillon B, Poncin-Epaillard F. Appl. Surf. Sci. 1997; 108: 177.

34) Simpson TRE, Tabatabaian Z, Jeynes C, Parbhoo B, Keddie JL. J. Pol. Sci: Pt. A: Polym. Chem. 2004; 42: 1421.

35) Simpson TRE, Parbhoo B, Keddie JL. Polymer 2003; 44: 4829.

36) Keddie JL. Curr. Opin. Coll. Interf. Sci. 2001; 6: 102.

37) Röseler A, Korte EH. Thin Sol. Films 1998; 313-314: 708.

38) Kim KJ, Cho YJ, Kim YH. Vibr. Spect. 1995; 9: 147.

39) Benedetti E et al. Polym. Intern. 1998; 45: 373.

40) Richardson H, Carelli C, Keddie JL, Sferrazza M. Eur. Phys. J. E 2003; 12: 437.

41) Wang CL, Zhong WL, Zhang PL. Synth. Metals 2003; 135-36: 469.

42) Cortili G, Zerbi G. Spectrochimica Acta 1967; 23A: 285.

43) Boerio FJ, Koenig JL. J. Polym. Sci: Pt. A-2 1971; 9: 1517.

44) O'Reilly JM, Mosher RA. Macromolecules 1981; 14: 602.

45) Koenig JL. In Spectroscopy of Polymers, American Chemical Society:

Washington, DC, 1992; Chapter 4.

46) Garcia-Caurel E, Drévillon, De Martino A, Schwartz L. Appl. Optics 2002; 41: 7339. 
Table I. Characteristic Absorption Frequencies for PMMA Observed in Figure 1a

$\begin{array}{lll}\text { Peak Number } & \text { Peak Position }\left(\mathrm{cm}^{-1}\right) & \text { Assignment }[44] \\ \text { i } & 748 & \gamma\left(\mathrm{CH}_{3}\right) \\ \text { ii } & 991 & \delta\left(\mathrm{CH}_{3}-\mathrm{O}\right) \\ \text { iii } & 1146 & \text { skeletal } \\ \text { v } & 1195 & \text { skeletal } \\ \text { vi } & 1242 & v(\mathrm{C}=\mathrm{O}) \\ \text { vii } & 1273 & \delta_{\mathrm{s}}\left(\alpha-\mathrm{CH} \mathrm{H}_{3}\right) \\ \text { viii } & 1385 & \delta_{\mathrm{s}}\left(\alpha-\mathrm{CH}{ }_{3}\right) \\ \text { ix } & 1450 & \delta(\mathrm{CH}) / \delta_{\mathrm{a}}\left(\mathrm{CH}_{3}-\mathrm{O}\right) \\ \text { x } & 1485 & \delta_{\mathrm{a}}(\alpha-\mathrm{CH}) \\ \text { xi } & 1720 & v(\mathrm{C}=\mathrm{O}) \\ & 1739 & v(\mathrm{C}=\mathrm{O})\end{array}$

Notation: $\gamma=$ wag deformation; $\delta=$ bending; $v=$ stretching; $\mathrm{s}=$ symmetric; $\mathrm{a}=$ asymmetric 
Table II. Characteristic Absorption Frequencies for PVDF Observed in Figure 1b

\begin{tabular}{|c|c|c|}
\hline Peak Number & Peak Position $\left(\mathrm{cm}^{-1}\right)$ & Assignment $[38,42,43]$ \\
\hline 1 & 756 & $\delta^{\mathrm{i}}\left(\mathrm{CF}_{2}\right)$ \\
\hline 2 & 794 & $\mathrm{r}^{\mathrm{i}}\left(\mathrm{CH}_{2}\right)$ \\
\hline 3 & 879 & $v_{\mathrm{s}}(\mathrm{C}-\mathrm{C})$ or trans* PVDF \\
\hline 4 & 964 & skeletal PVDF \\
\hline 5 & 1065 & $v_{\mathrm{a}}(\mathrm{C}-\mathrm{C})$ (or skeletal) \\
\hline 6 & 1152 & $\mathrm{r}^{\mathrm{o}}\left(\mathrm{CH}_{2}\right)$ \\
\hline 7 & 1173 & $v_{a}^{i}\left(C F_{2}\right)$ \\
\hline 8 & 1242 & $v_{\mathrm{a}}^{\mathrm{o}}\left(\mathrm{CF}_{2}\right) / v_{\mathrm{s}}^{\mathrm{i}}\left(\mathrm{CF}_{2}\right)$ \\
\hline 9 & 1373 & $v_{\mathrm{s}}^{\mathrm{o}}\left(\mathrm{CF}_{2}\right)$ \\
\hline 10 & 1411 & $\gamma\left(\mathrm{CH}_{2}\right)$ \\
\hline
\end{tabular}

Notation: $\mathrm{r}=$ rocking; $\gamma=$ wag deformation; $\mathrm{v}=$ stretching; $\delta=$ bending; a $=$ asymmetric; $\mathrm{s}=$ symmetric; $\mathrm{i}=$ in-phase $; \mathrm{o}=$ out-of-phase

* characteristic of the short trans sequence of PVDF [38] 
Table III. Gain and Loss Peaks in Figure 6 Obtained after Heating a PMMA/PVDF Bilayer at $190{ }^{\circ} \mathrm{C}$ for $30 \mathrm{~s}$

$\begin{array}{cccc}\text { Peak Number* } & \text { Type } & \underline{\text { Peak Position }\left(\mathrm{cm}^{-1}\right)} & \underline{\text { Assignment }} \\ 3 & \text { Loss } & 879 & v_{\mathrm{s}}(\mathrm{C}-\mathrm{C}) / \text { trans PVDF } \\ 6 & \text { Gain } & 1165 & \mathrm{r}^{\mathrm{o}}\left(\mathrm{CH}_{2}\right) \\ 8 & \text { Gain } & 1219 & v_{\mathrm{a}}^{\mathrm{o}}\left(\mathrm{CF}_{2}\right) \\ 9 & \text { Gain } & 1400 & v_{\mathrm{s}}^{\mathrm{o}}\left(\mathrm{CF}_{2}\right) / v_{\mathrm{s}}^{\mathrm{i}}\left(\mathrm{CF}_{2}\right) \\ 10 & \text { Gain } & 1439 & \gamma\left(\mathrm{CH}_{2}\right) \\ \mathrm{x} & \text { Loss } & 1720 & \gamma(\mathrm{C}=\mathrm{O}) \\ \mathrm{xi} & \text { Loss } & 1739 & \gamma(\mathrm{C}=\mathrm{O})\end{array}$

\footnotetext{
* Compare to Tables I and II
} 
Table IV. Gain and Loss Peaks in Figure 8 Obtained after Heating a PVDF/PMMA Bilayer at $190{ }^{\circ} \mathrm{C}$ for $30 \mathrm{~s}$

\begin{tabular}{|c|c|c|c|}
\hline Peak Number* & Type & Peak Position $\left(\mathrm{cm}^{-1}\right)$ & Assignment \\
\hline $\mathrm{i}$ & Gain & 764 & $\gamma\left(\mathrm{CH}_{3}\right)$ \\
\hline $3 * *$ & Loss & 914 & $v_{\mathrm{s}}(\mathrm{C}-\mathrm{C})$ or PVDF trans \\
\hline $4 * *$ & Loss & 980 & PVDF skeletal \\
\hline iii & Gain & 1152 & PMMA skeletal \\
\hline vii & Gain & 1381 & $\delta_{\mathrm{s}}\left(\alpha-\mathrm{CH}_{3}\right)$ \\
\hline
\end{tabular}




\section{Figure Captions}

Figure 1. IR ellipsometry spectra $(\tan (\psi)$ at the top and $\cos (\Delta)$ at the bottom) for (a) a bare Si substrate and a $590 \mathrm{~nm}$ PMMA film on Si; and (b) a $547 \mathrm{~nm}$ PVDF film on Si. The angle-of-incidence for all experiments was $65^{\circ}$. The characteristic absorptions are identified by numbers (Roman and Arabic) that are assigned as listed in Tables I and II.

Figure 2. IR ellipsometry spectra $(\tan (\psi)$ at the top and $\cos (\Delta)$ at the bottom) for a bilayer of PMMA on PVDF on a silicon substrate (PVDF/Si), before (gray line) and after (black line) heating at $190{ }^{\circ} \mathrm{C}$ for $30 \mathrm{~s}$.

Figure 3. Simulated IR ellipsometry spectra $(\tan (\psi)$ at the top and $\cos (\Delta)$ at the bottom) for a bilayer of a $300 \mathrm{~nm}$ PDMS film on a $300 \mathrm{~nm}$ PMMA film on a silicon substrate (solid line) and for a $600 \mathrm{~nm}$ blend film on a silicon substrate (dashed line).

Figure 4. Simulated $\operatorname{Re} D$ (top) and $\operatorname{Im} D$ (bottom) spectra for a $600 \mathrm{~nm}$ PDMSPMMA blend film (solid line) and a $600 \mathrm{~nm}$ gradient film (dashed line), as described in the text. Both simulations used a bilayer of a $300 \mathrm{~nm}$ PDMS film on a $300 \mathrm{~nm}$ PMMA film as the original structure.

Figure 5. Simulated $\operatorname{Re} D$ (top) and $\operatorname{Im} D$ (bottom) spectra for a $600 \mathrm{~nm}$ PDMSPMMA bilayer with a $100 \mathrm{~nm}$ blended layer at the interface. The simulations used a $300 \mathrm{~nm}$ PDMS/300 nm PMMA bilayer as the original structure. 
Figure 6. The ellipsometric density spectra ( $\operatorname{Re} D$ at the top and $\operatorname{Im} D$ at the bottom) for the same bilayer that was analysed in Figure 2 after heating at $190{ }^{\circ} \mathrm{C}$ for $30 \mathrm{~s}$ (black line). The bilayer was heated at $190{ }^{\circ} \mathrm{C}$ for an additional four min. $\mathrm{Re} D$ and $\operatorname{Im} D$ are shown for a comparison to the state after $30 \mathrm{~s}$. of heating (gray line).

Figure 7. The ellipsometric density spectra ( $\operatorname{Re} D$ at the top and $\operatorname{Im} D$ at the bottom) for bilayer films of PMMA on PVDF/Si at temperatures ranging from 155 to $185^{\circ} \mathrm{C}$ in $5^{\circ} \mathrm{C}$ increments. Temperature increases going from the bottom spectra to the top spectra. The $D$ spectra were obtained by comparing data to that at the previous temperature $\left(5^{\circ} \mathrm{C}\right.$ lower). The spectra are shifted vertically for clarity. The gain peak at $1203 \mathrm{~cm}^{-1}$ is attributed to the $\delta(\mathrm{C}-\mathrm{F})$ vibration of PVDF that has diffused to the surface.

Figure 8. Ellipsometric density ( $\operatorname{Re} D$ at the top and $\operatorname{Im} D$ at the bottom) for a PVDF film on PMMA/Si after heating at $190{ }^{\circ} \mathrm{C}$ for $30 \mathrm{~s}$. (black line) and after heating at four min. (gray line). Spectra are inverted in comparison to Figure 3.

Figure 9. The ellipsometric density spectra $(\operatorname{Re} D$ at the top and $\operatorname{Im} D$ at the bottom) for bilayer films of PVDF on PMMA/Si at temperatures ranging from 155 to $185^{\circ} \mathrm{C}$ in $5{ }^{\circ} \mathrm{C}$ increments (moving from the bottom to the top spectra). The temperature was held for $15 \mathrm{~min}$. at each temperature. The $D$ spectra were obtained by comparing data to that at the previous temperature $\left(5^{\circ} \mathrm{C}\right.$ lower $)$. The spectra are shifted vertically for clarity. 

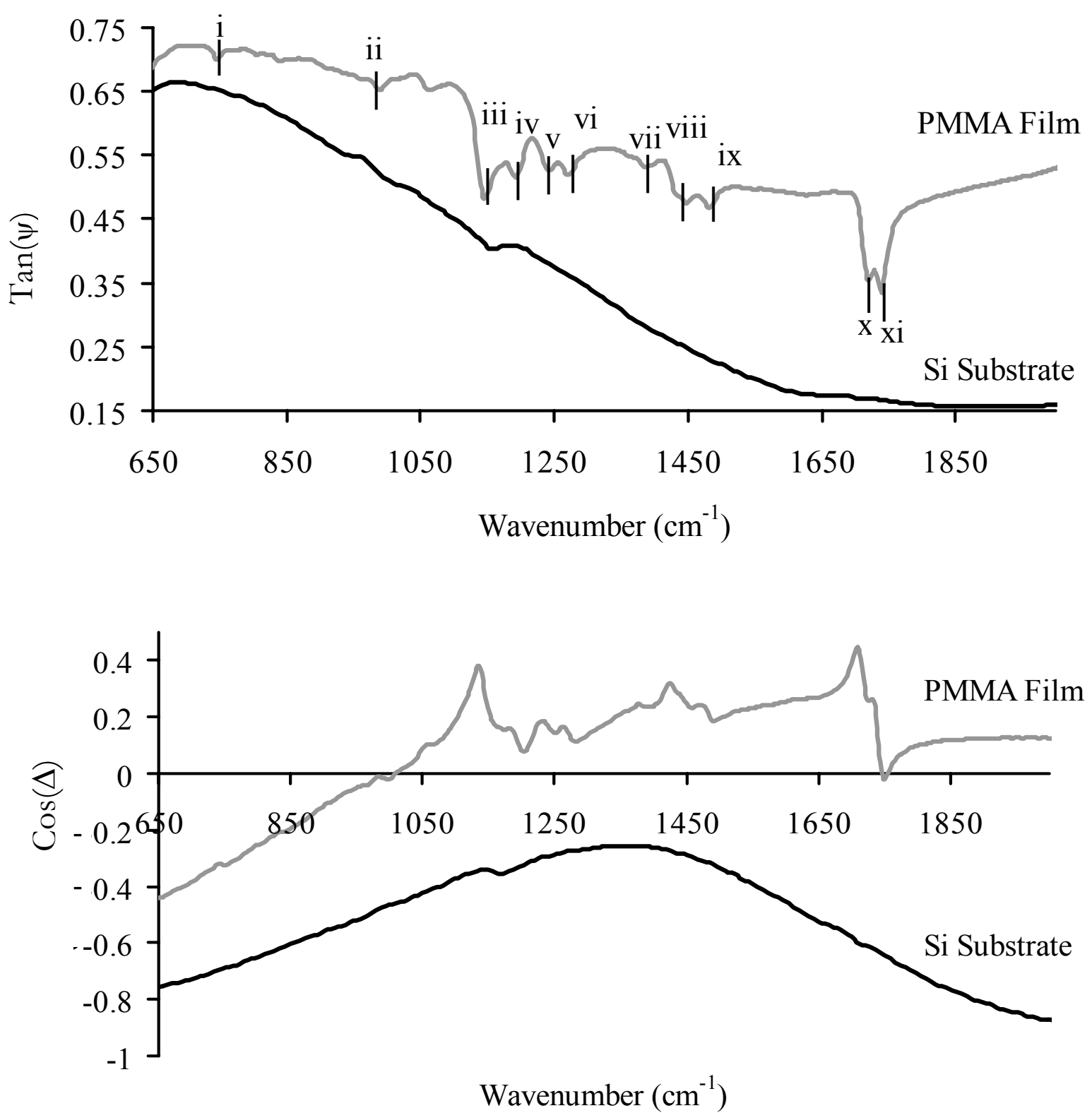

Figure 1a, Duckworth et al. 

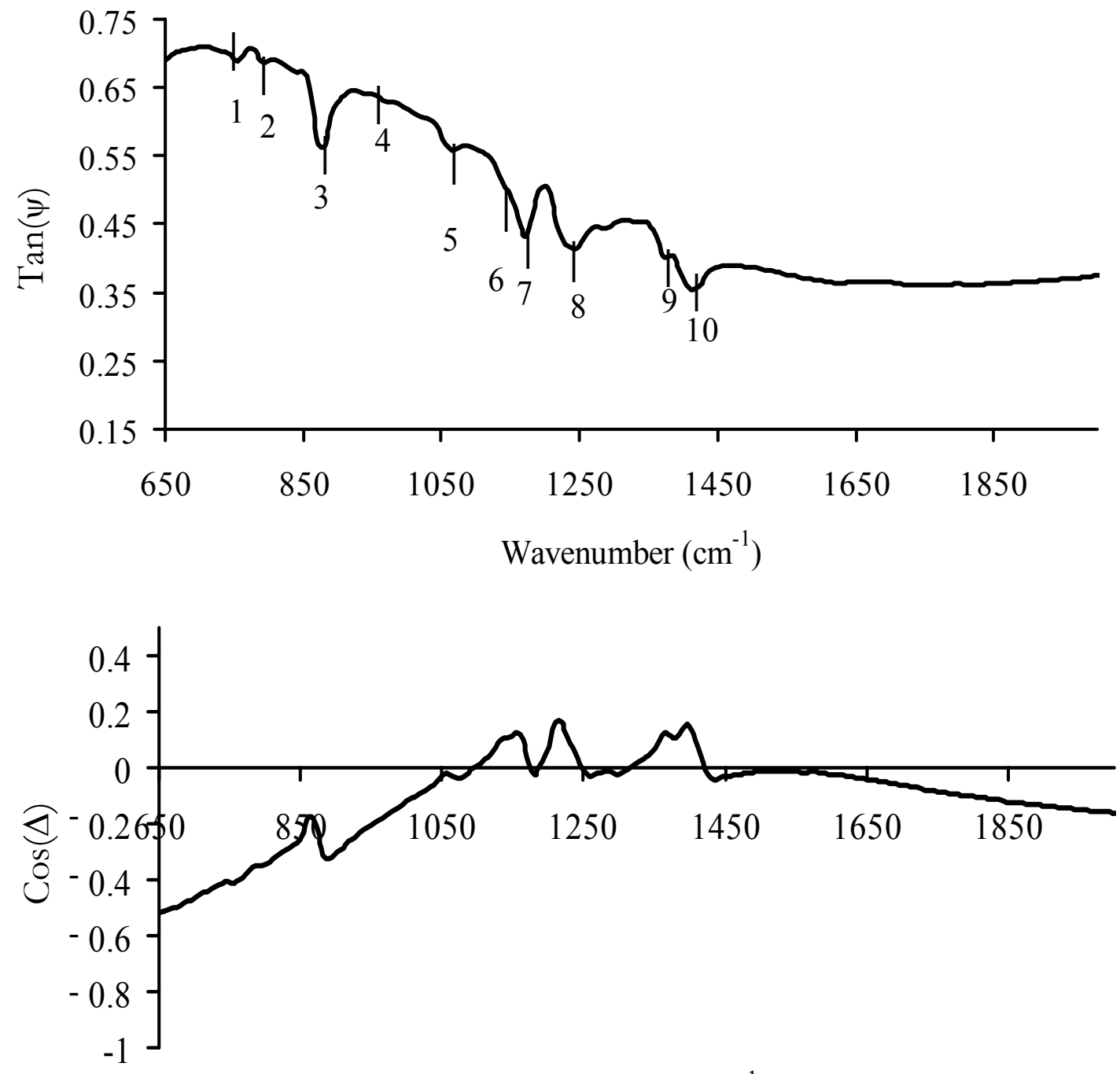

Wavenumber $\left(\mathrm{cm}^{-1}\right)$

Figure 1b, Duckworth et al. 

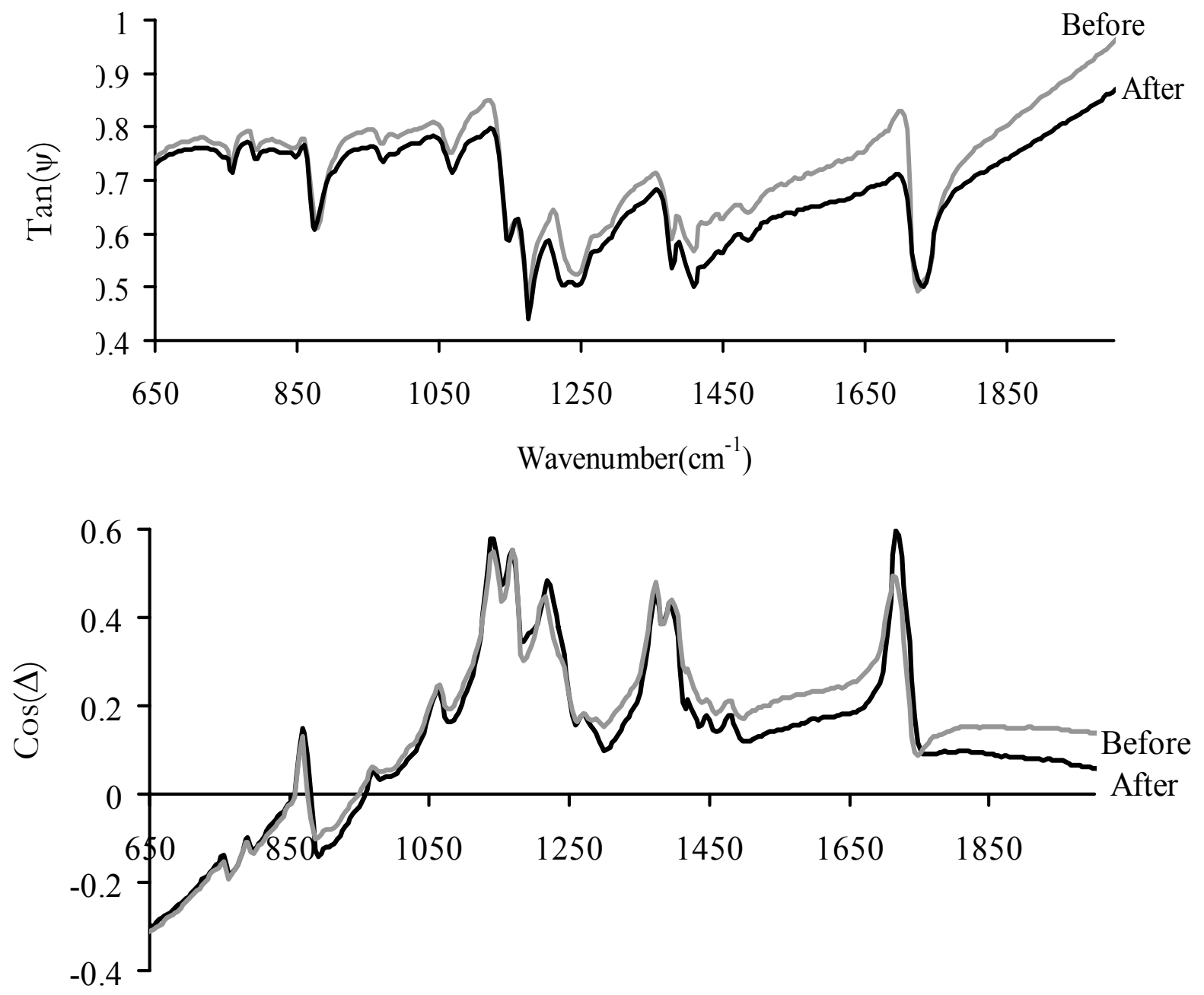

Wavenumber $\left(\mathrm{cm}^{-1}\right)$

Figure 2, Duckworth et al. 

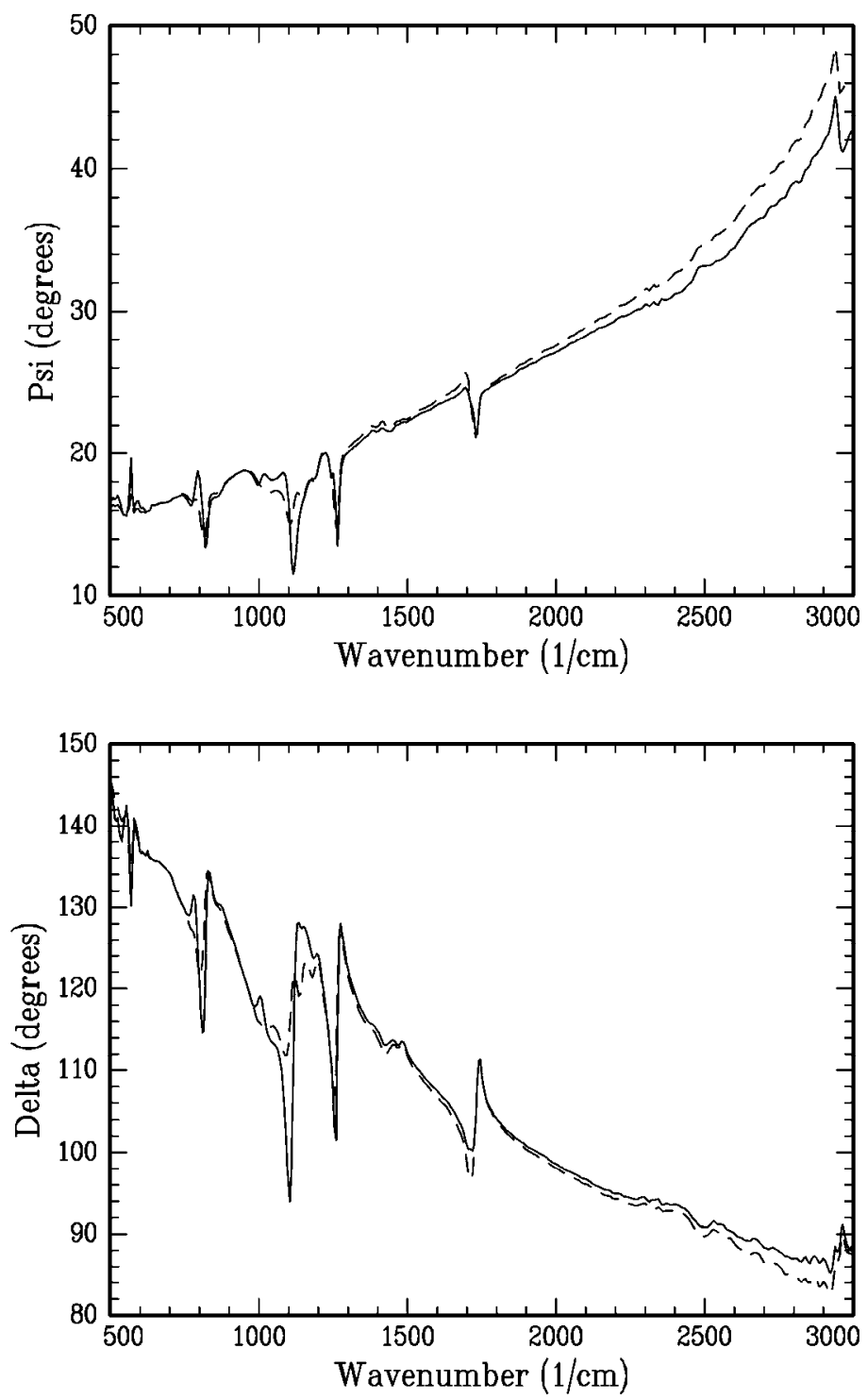

Figure 3, Duckworth et al. 

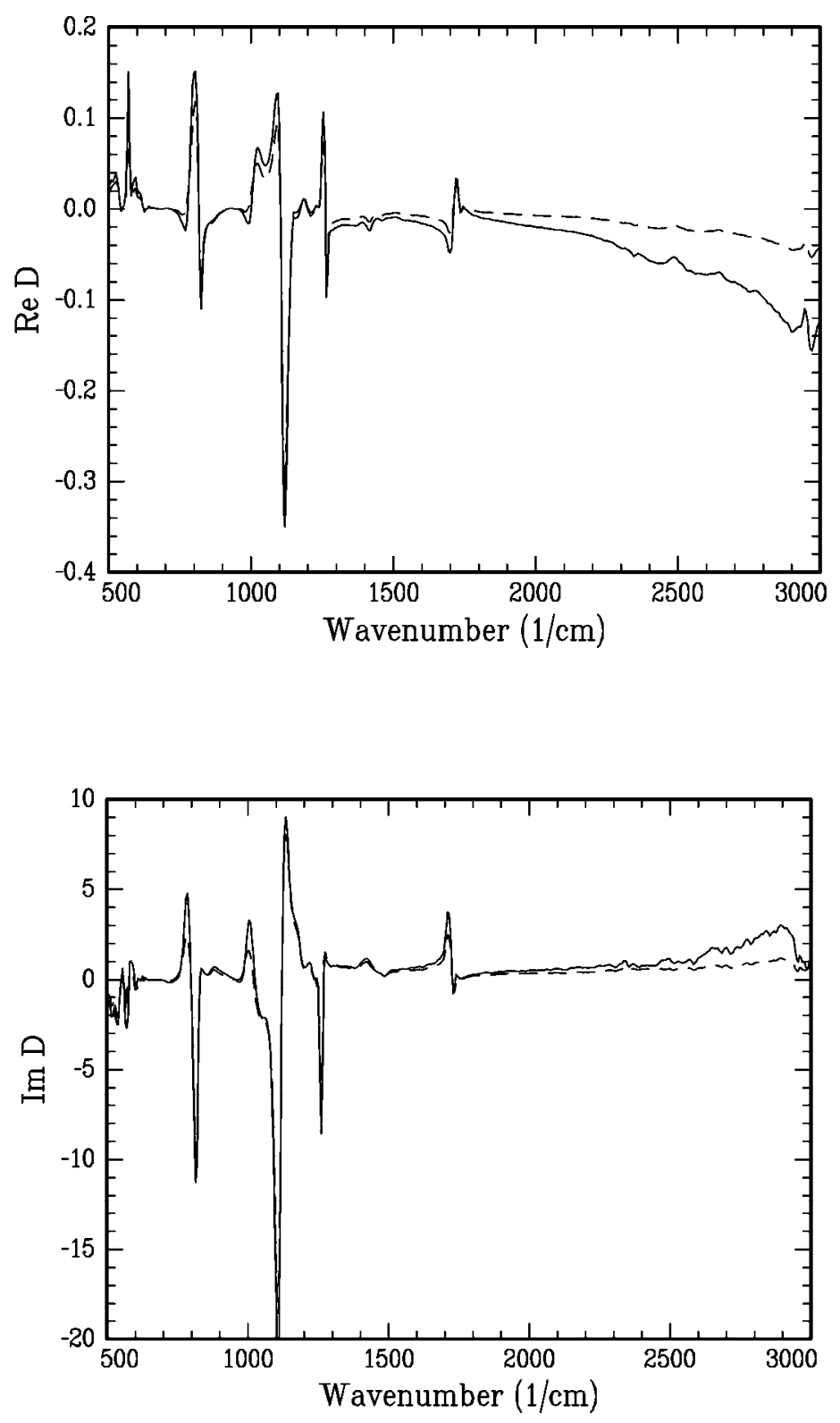

Figure 4, Duckworth et al. 

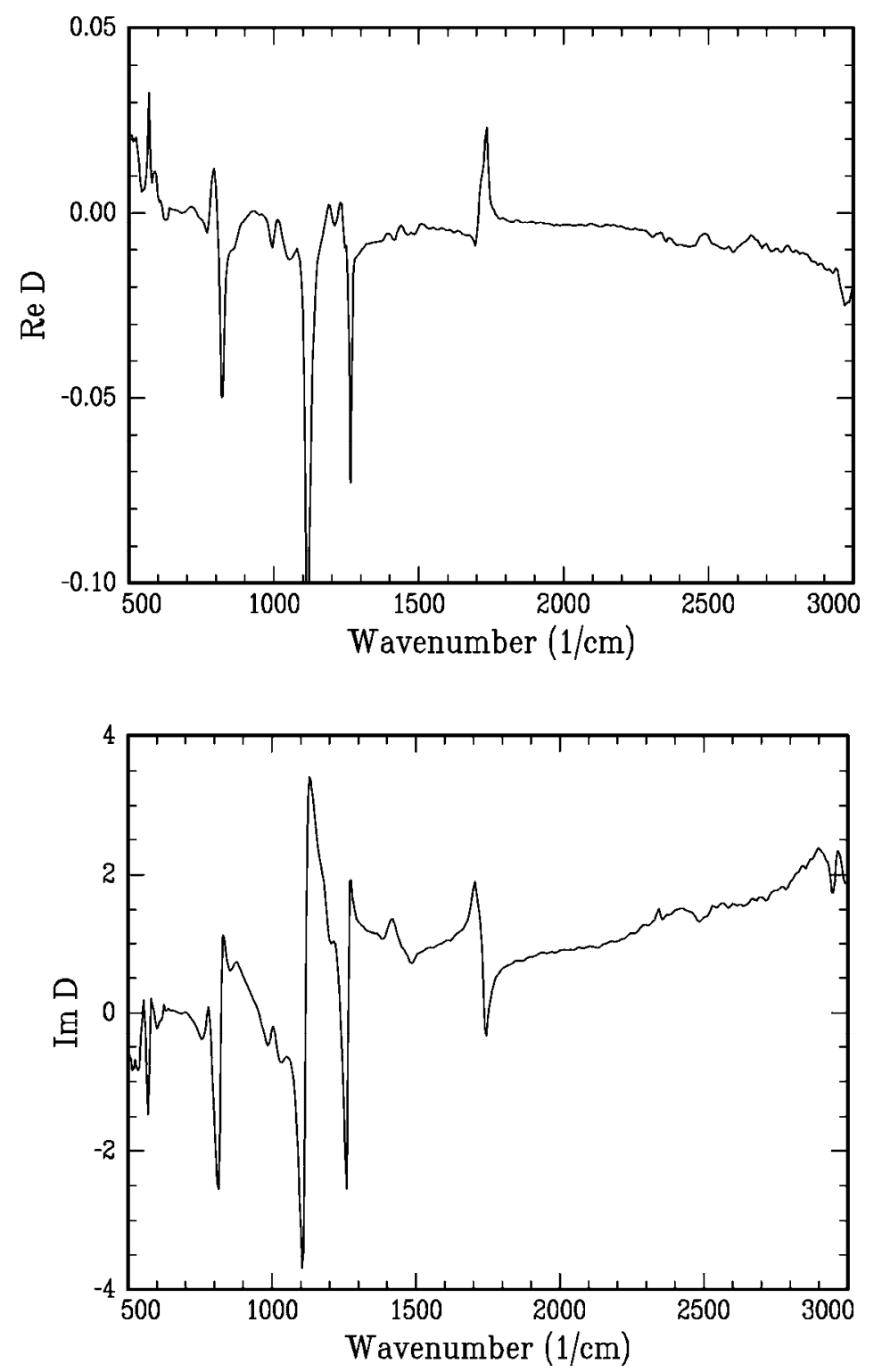

Figure 5, Duckworth et al. 

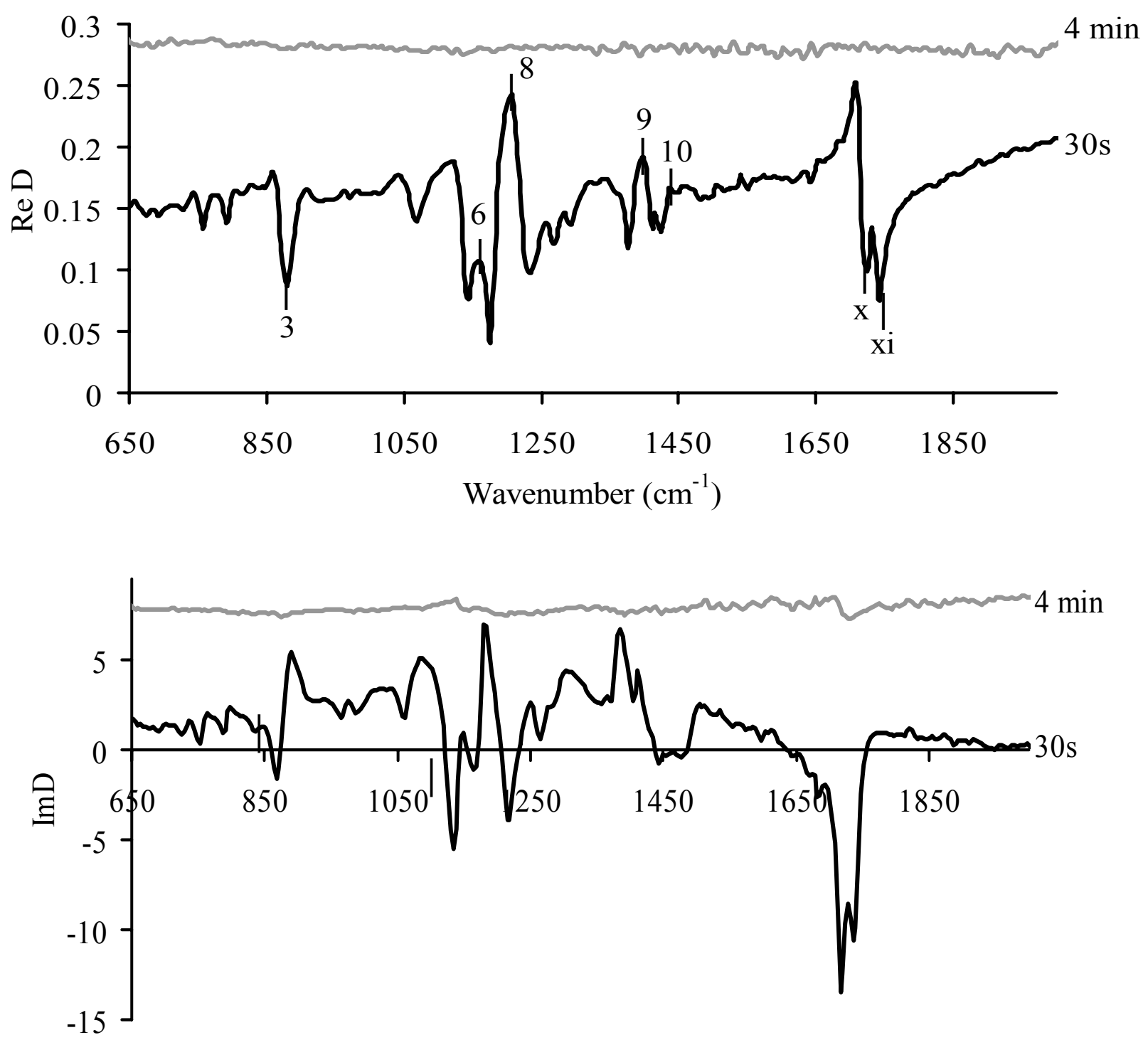

Wavenumber $\left(\mathrm{cm}^{-1}\right)$

Figure 6, Duckworth et al. 

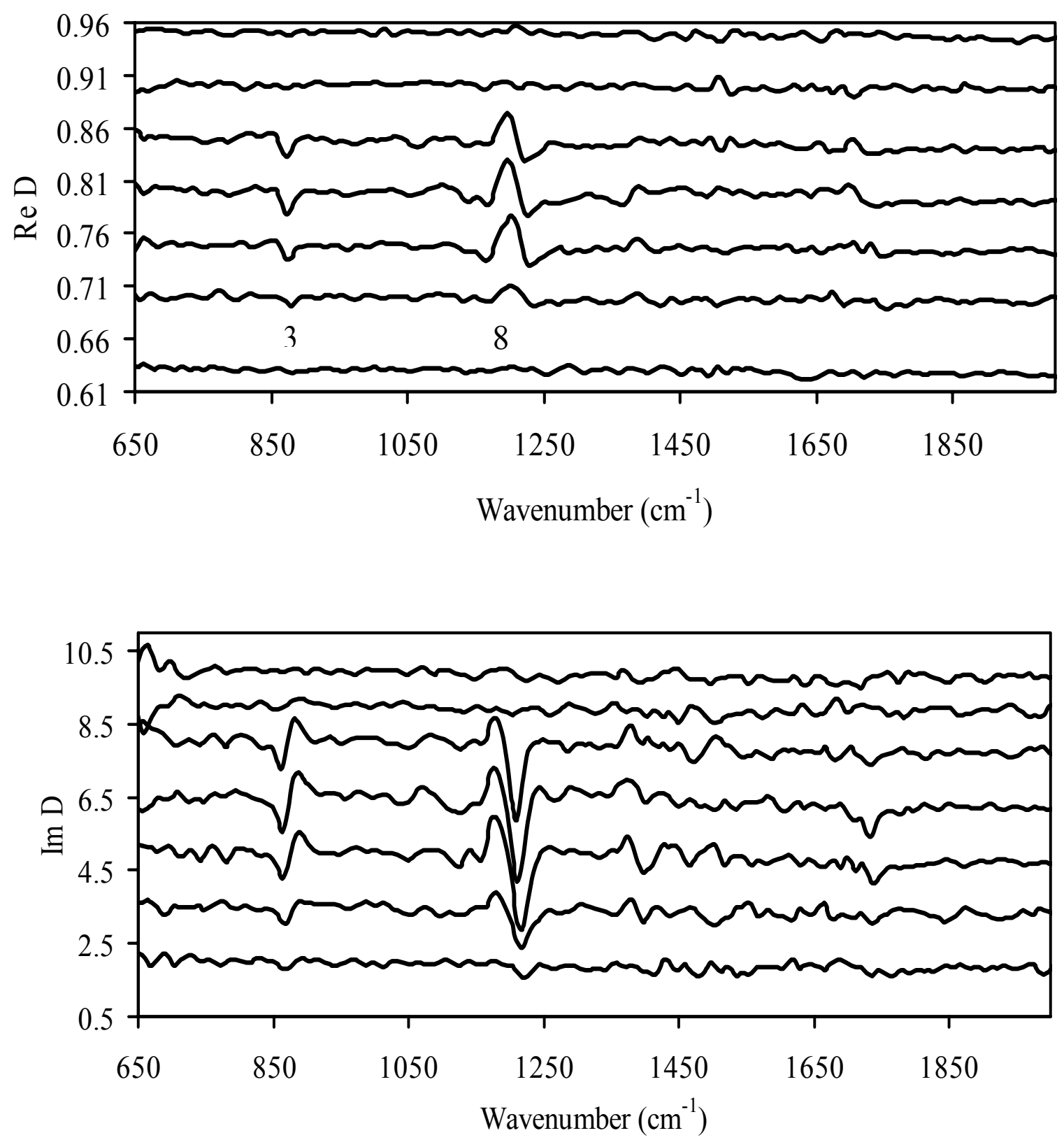

Figure 7, Duckworth et al. 

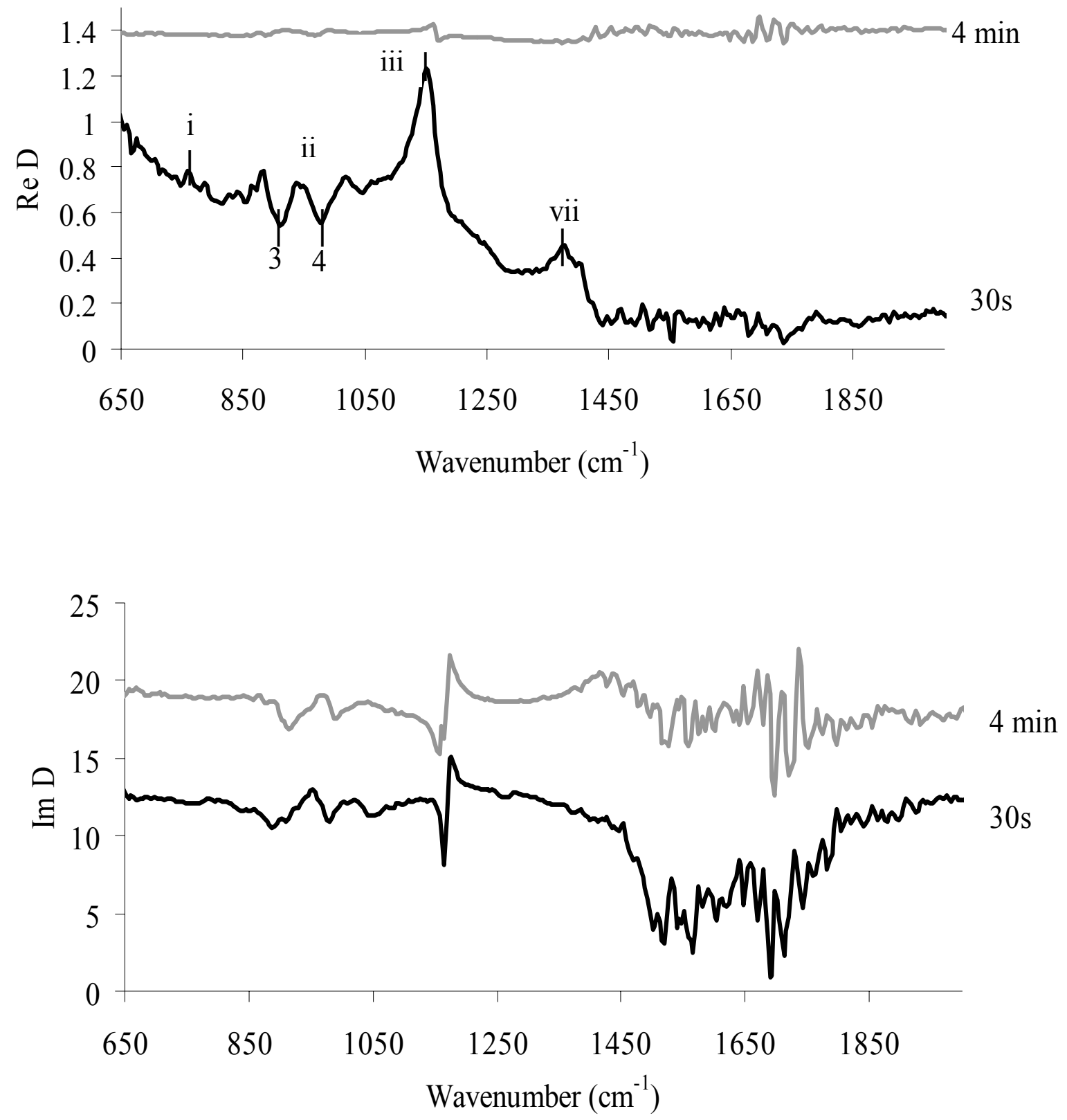

Figure 8, Duckworth et al. 

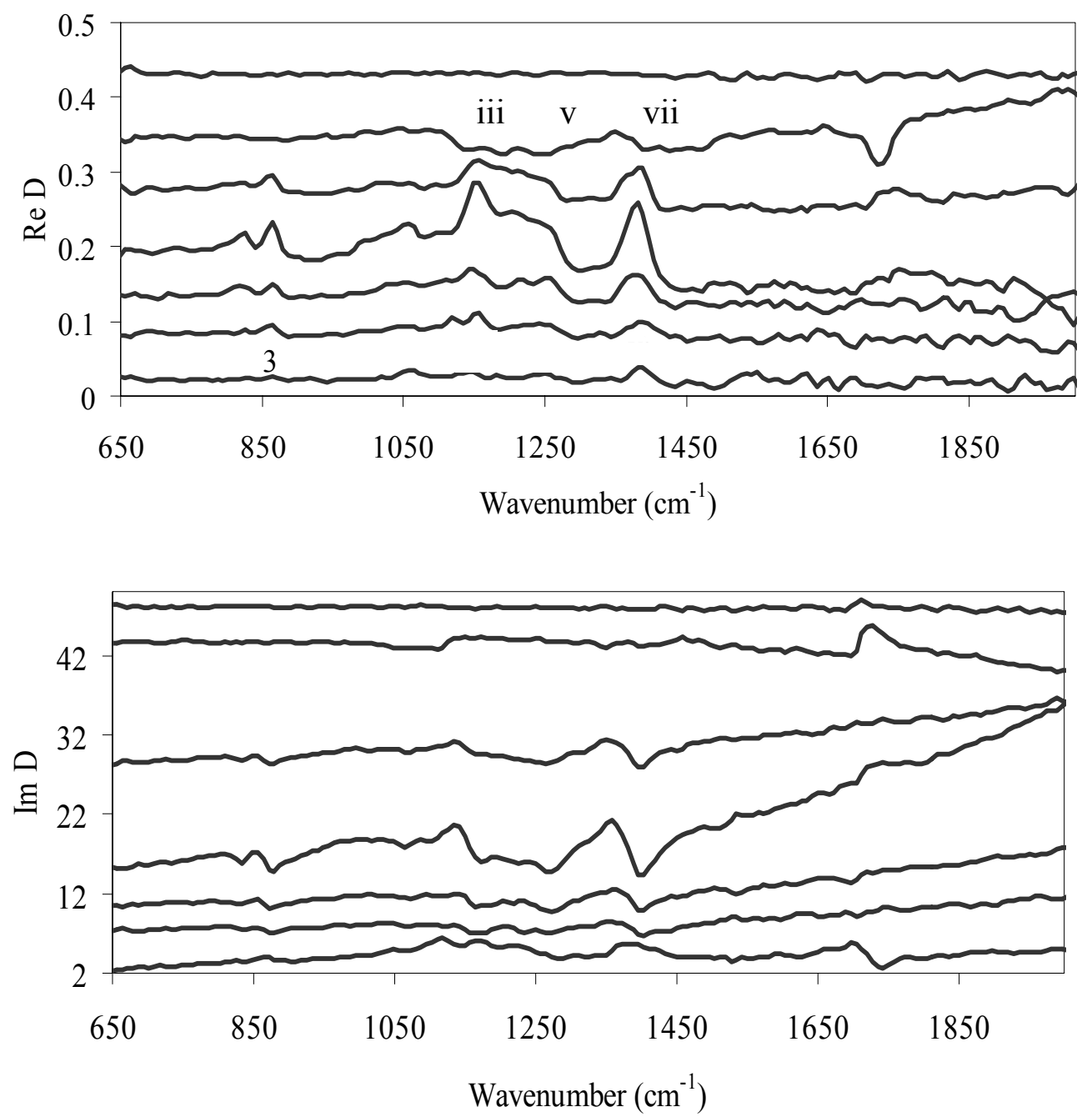

Figure 9, Duckworth et al. 